\title{
Preparation and evaluation of mebeverine hydrochloride as mucoadhesive buccal tablet for local anesthesia
}

\author{
Seham S Abdulhady ${ }^{1 \star}$ and Khaled M Hosny Ibrahim $^{2}$ \\ ${ }^{1}$ Department of Pharmaceutics and Industrial Pharmacy, Faculty of Pharmacy, King Abdulaziz University, Jeddah, Saudi \\ Arabia, ${ }^{2}$ Department of Pharmaceutics and Industrial Pharmacy, Faculty of Pharmacy, Beni-Suef University, Beni-Suef, Egypt \\ *For correspondence: Email: Sehamhady@gmail.com; Tel: 00966551849789
}

Sent for review: 6 January 2017

Revised accepted: 8 July 2017

\begin{abstract}
Purpose: To formulate and evaluate an antispasmodic drug, mebeverine hydrochloride (Mbv-HCl), as a local anesthetic mucoadhesive buccal tablet.

Methods: $\mathrm{Mbv}-\mathrm{HCl}$ loaded tablets were formulated, using a direct compression technique, with varying polymer concentrations including carbopol 934P alone, carbopol 934P/hydroxypropyl methylcellulose (HPMC) mixture, or carbopol 934P/chitosan mixture. The tablets were evaluated for physicochemical characteristics, in-vitro drug release, bioadhesive strength, swelling, ex-vivo residence time, ex-vivo permeation, drug permeation through the buccal membrane of sheep, and stability.

Results: The results indicate that formulation F4, which contains HPMC/carbopol 934P (3:1), showed the best in-vitro drug release profile. The release kinetics for all the formulations fitted well with HixsonCrowell kinetic model. Bioadhesive strength, surface $\mathrm{pH}$, and swelling index of F4 were 41.52, 6.36, and $231.2 \%$, respectively. Maximum residence time ex-vivo was exhibited by formulation F4, showing a maximum residence time of about 330 min with $80 \%$ of $\mathrm{Mbv}-\mathrm{HCl}$ permeated in $6 \mathrm{~h}$ ex-vivo. F4 was stable after storage for 60 days at $25^{\circ} \mathrm{C} / 60 \% \mathrm{RH}$ and $40^{\circ} \mathrm{C} / 75 \% \mathrm{RH}$, with non-significant change $(p<$ $0.05)$ in drug content, bioadhesive strength and in vitro release.

Conclusion: The optimized mucoadhesive buccal formulation is promising for delivery of $\mathrm{Mbv}-\mathrm{HCl}$, and displays high bioadhesion and adequate permeability through sheep buccal membrane to achieve a local anesthetic action.
\end{abstract}

Keywords: Mebeverine hydrochloride, Buccal, Mucoadhesive tablet, Swelling index, Bioadhesive strength, Local anesthetic

Tropical Journal of Pharmaceutical Research is indexed by Science Citation Index (SciSearch), Scopus, International Pharmaceutical Abstract, Chemical Abstracts, Embase, Index Copernicus, EBSCO, African Index Medicus, JournalSeek, Journal Citation Reports/Science Edition, Directory of Open Access Journals (DOAJ), African Journal Online, Bioline International, Open-J-Gate and Pharmacy Abstracts

\section{INTRODUCTION}

Mebeverine hydrochloride (Mbv- $\mathrm{HCl})$ is an antispasmodic agent reported to have a strong local anesthetic activity with insignificant side effects when compared to other local anesthetics [1]. It is a crystalline powder, white in color, with good solubility in ethanol and water [2].

A non-specific relaxant effect on vascular, cardiac and other smooth muscle is shown by $\mathrm{Mbv}-\mathrm{HCl}$ [3]. Previous literature revealed that the activity of $\mathrm{Mbv}-\mathrm{HCl}$ as a spasmolytic is not due to one particular system. $\mathrm{Mbv}-\mathrm{HCl}$ has a polyvalent spasmolytic action where about three different mechanisms are involved. Detailed study and explanation of these mechanisms have been previously described by Hameed et al [4].

In dental procedures, topical local anesthetic agents are applied in order to ensure a painless treatment without the distress associated with needle injections for gingival or periodontal therapies [5]. Formulations need to have easy 
application, remain on the applied tissue, and have sufficient effectiveness and stable storage. Topical anesthetics are used in the medical field to reduce the pain of operative procedures, to relieve the pain of superficial mucosal lesions, such as ulcers, to mask the discomfort of injections, and to anesthetize skin prior to vein puncture for general anesthesia or sedation [6]. Local anesthetics for topical application can be mixed with a number of different formulations. Efficacy can be affected by the type of preparation, such as thru sprays, emulsions, film strips, patches, and creams [7].

Transmucosal drug delivery systems are designed with mucoadhesive polymers that have specific characteristics such as high viscosity, molecular weight, long chain length, and flexibility of chain length [8]. Hydrophilic polymers and gelling agents are the most common components of broad classes of mucoadhesive polymers [9]. Hydrophilic polymers containing a carboxylic group exhibit better mucoadhesive characters, such as cellulose derivatives [10].

Hydrogels, the other class of polymeric biomaterial, exhibit the basic characteristics of a hydrogel by swelling as it absorbs water, which leads to adhesion with the epithelial mucus, i.e., chitosan and polyacrylates [11]. Formulation of $\mathrm{Mbv}-\mathrm{HCl}$ into suitable topical mucoadhesive tablets for local application to superficial mucosal is used to control various painful oral conditions. This approach consists of using several mucoadhesive polymers, such as chitosan, carbopol 934, and HPMC to provide sufficient residence time for the tablets.

Contemporary research is primarily addressing the problem of retention by the delivery system in the oro-mucosal space over longer durations. Moreover, $\mathrm{Mbv}-\mathrm{HCl}$ must be released in a controlled fashion to achieve pharmacological responses. Accordingly, the aim of this work was to develop anesthetic bioadhesive tablets containing $\mathrm{Mbv}-\mathrm{HCl}$. Additionally, we studied exvivo buccal permeation through the buccal membrane of sheep and in vitro. The objective of this research was to formulate and evaluate mucoadhesive oral formulations of $\mathrm{Mbv}-\mathrm{HCl}$, which is an antispasmodic agent for use as a buccal anesthetic tablet.

\section{EXPERIMENTAL}

\section{Materials}

Mebeverine hydrochloride was obtained from MOEHS Fine Chemicals, Cantabria, Spain. Hydroxypropyl methylcellulose (HPMC) and carbopol 934P were purchased from Aqualon, United Kingdom. Chitosan was obtained from Fluka, U.SA while Avicel and magnesium stearate were purchased from Sigma-Aldrich, USA.

\section{Formulation of mucoadhesive buccal tablets}

$\mathrm{Mbv}-\mathrm{HCl}$ tablet formulations of varying compositions were manufactured with a direct compression method using compaction equipment (ERWEKA, GmbH, AR 402, Germany) [12], according to Table 1.

\section{Evaluation of mucoadhesive buccal $\mathrm{Mbv}-\mathrm{HCl}$ tablets}

\section{Weight variation}

Approximately, a batch of ten tablets from different formulations was weighed (Erweka EB 100, Germany) and the mean weight was calculated and reported.

\section{Hardness}

Tablets were taken randomly from each batch and tested for hardness. The tablet hardness tester (Erweka TBH 200, Germany) was helpful for determining the actual strength required to make a visible fracture on a tablet. A vernier caliper (pre-calibrated) was used to measure thickness and diameter.

Table 1: Composition of $\mathrm{Mbv}-\mathrm{HCl}$ mucoadhesive buccal tablets

\begin{tabular}{llllllll}
\hline Ingredient (mg) & F1 & F2 & F3 & F4 & F5 & F6 & F7 \\
\hline Mbv-HCL & 100 & 100 & 100 & 100 & 100 & 100 & 100 \\
Carbopol 934P & 100 & 75 & 50 & 25 & 75 & 50 & 25 \\
HPMC & 0 & 25 & 50 & 75 & 0 & 0 & 0 \\
Chitosan & 0 & 0 & 0 & 0 & 25 & 50 & 75 \\
Mannitol & 30 & 30 & 30 & 30 & 30 & 30 & 30 \\
Avicel & 65 & 65 & 65 & 65 & 65 & 65 & 65 \\
Mg Stearate & 5 & 5 & 5 & 5 & 5 & 5 & 5 \\
\hline Total weight & $\mathbf{3 0 0}$ & $\mathbf{3 0 0}$ & $\mathbf{3 0 0}$ & $\mathbf{3 0 0}$ & $\mathbf{3 0 0}$ & $\mathbf{3 0 0}$ & $\mathbf{3 0 0}$ \\
\hline
\end{tabular}


The tester plunger was rolled down at a speed of $20 \mathrm{~mm} / \mathrm{min}$. Crushing strength $(T)$ as a measure of tensile strength was calculated as in Eq 1.

$\mathrm{T}=2 \mathrm{~F} / \pi \mathrm{dt}$

where $\mathrm{F}$ is referred as crushing load, and $\mathrm{t}$ and $\mathrm{d}$ denote the thickness and diameter of each tablet, respectively.

\section{Friability}

Approximately twenty tablets from different formulations were weighed and put onto the drum of an Erweka Friabilator, type PTF1 (Pharmatest, Hainburg, Germany). After 100 revolutions of the drum, the tablets were dedusted and weighed [13]. Friability was calculated as the difference in weight, expressed as a percentage.

\section{Thickness}

Approximately ten tablets from different formulations were measured with the help of a digital micrometer (Mitutoyo Co., Kawasaki, Japan), and mean thickness was calculated.

\section{Content uniformity}

Ten tablets were taken from each formulation. This step was followed by crushing and mixing. Two-hundred $\mathrm{mg}$ of $\mathrm{Mbv}-\mathrm{HCl}$ from the mixture were extracted using $100 \mathrm{~mL}$ of $0.1 \mathrm{M}$ hydrochloric acid and then heated for $10 \mathrm{~min}$ in a water-bath (GFL Corporation; Model 1031, Germany) and shaken frequently.

Sufficient $0.1 \mathrm{M}$ hydrochloric acid was used to produce $250 \mathrm{~mL}$ that was added and then filtered [13]. The final solution absorbance was measured at $\lambda_{\max } 263 \mathrm{~nm}$ using an ultravioletvisible spectrophotometer (Perkin Elmer, Shelton, USA).

\section{Microenvironment (superficial) pH}

Irritation of the buccal mucosa may be produced by the acidic or alkaline surface $\mathrm{pH}$ of the buccal tablets, and therefore must be kept as close to neutral as possible. The tablet was taken with 5 $\mathrm{mL}$ distilled water and allowed to swell for $2 \mathrm{~h}$. The $\mathrm{pH}$ was recorded while maintaining contact with a combined glass electrode for $1 \mathrm{~min}$. (Erweka pH1004, Germany).

\section{Bioadhesion studies}

In the present experiment, fresh sheep buccal mucosa was used as a model mucosal surface to test bioadhesion strength. The local Institutional Review Board (L.I.R.B) for pre and veterinary research approved the experiments as per EU Directive- 2010 / 63 / EU on the basis of protection of animals used for scientific purposes (DHEW publication NIH 80 - 23). The experiments also adhered to the Principles of Laboratory Animal Care (NIH publication \# 85 23, 1985 (revised)[16]. Fresh buccal mucosa was taken from sheep and transported in a tyrode solution, with a composition comprised of glucose, sodium bicarbonate $\left(\mathrm{NaHCO}_{3}\right)$ approx. $1.0 \mathrm{~g} / \mathrm{L}$ and sodium chloride $(\mathrm{NaCl})$, potassium chloride $(\mathrm{KCl})$, calcium chloride dihydrate $\left(\mathrm{CaCl}_{2} \cdot 2 \mathrm{H}_{2} \mathrm{O}\right)$, and monosodium phosphate $\left(\mathrm{NaH}_{2} \mathrm{PO}_{4}\right)$ in $8,0.2,0.134,0.05 \mathrm{~g} / \mathrm{L}$, respectively at $40{ }^{\circ} \mathrm{C}$ [14]. Adhesion was measured as in Eq 2.

Force of adhesion $(\mathrm{N})=$ (Bioadhesive strength/100)9.81

\section{Ex-vivo residence time}

The mean residence time ex-vivo was determined using a modified USP II dissolution apparatus. A phosphate buffer of $\mathrm{pH} 6.8$ was selected as dissolution medium for the release studies at $37{ }^{\circ} \mathrm{C}$. Sheep buccal mucosa was mounted onto the glass surface and was attached to the apparatus.

One side of the three tablets of each patch were hydrated by $15 \mu \mathrm{L}$ buffer at $\mathrm{pH}$ 6.8. The hydrated surface was attached to contact with buccal mucosa. The secured tablets were immersed in the buffer solution. The paddle of the apparatus was set at $25 \mathrm{rpm}$ and adjusted at a distance of 5 $\mathrm{cm}$ from the tablet [15]. Mucosal erosion or detachment time was determined.

\section{Swelling test}

Swelling studies were conducted on approximately six buccal tablets. The tablets were weighed $\left(\mathrm{W}_{1}\right)$ and placed individually in 5 $\mathrm{mL}$ of phosphate buffer of $\mathrm{pH} 6.8$ in glass petri dishes. Further, each tablet was removed slowly from the petri dish by removing the excess water. The removal was performed at 1, 2, 4, 6, 8 and $12 \mathrm{~h}$ using filter paper. Hydration $(\mathrm{H})$ of the tablets was computed as the difference in tablet weight before and after swelling, expressed as a percentage.

\section{In-vitro dissolution test}

The USP paddle II method was adopted to perform in-vitro study. Phosphate buffer at $\mathrm{pH}$ 6.8 of approximately $450 \mathrm{~mL}$ was used as 
dissolution medium at $37 \pm 0.5^{\circ} \mathrm{C}$, with paddle speed at $50 \mathrm{rpm}$ (Erweka, DT $700 \mathrm{LH}$, Germany) [15]. At time intervals ( 1 to $12 \mathrm{~h}$ ) $5 \mathrm{~mL}$ samples were withdrawn. $\mathrm{Mbv}-\mathrm{HCl}$ content was measured by an ultraviolet-visible spectrophotometer (Perkin Elmer, Shelton, USA) at $\lambda_{\max } 263 \mathrm{~nm}$.

\section{Kinetic studies}

Kinetic studies are useful for understanding and determining the exact drug release rate and mechanism for various formulations. The following equations and models were applied for prediction:

\section{Zero-order kinetic model:}

If the drug does not disaggregate in the dissolution, then those results in slow drug release can be equated by

$Q_{t}=Q_{0}+K_{0} t$

$Q_{t}$ is drug concentration dissolved in time $t, Q_{0}$ is initial drug concentration in the solution (most times, $Q_{0}=0$ ) and $K_{0}$ is the constant (zero order release) (concentration / time).

First-order kinetic model:

$\log C=\log C_{0}-K t / 2.303$

where, $\mathrm{C}_{0}$ is initial drug concentration, $\mathrm{k}$ is constant (first order rate); $\mathrm{t}$ is the time.

Higuchi model:

$f_{t}=Q=K H \cdot t_{1 / 2}$

where, $\mathrm{KH}$ is Higuchi dissolution constant, $\mathrm{Q}$ is drug concentration per time $t$ and per unit area $A$.

Korsmeyer-Peppas model:

$\mathrm{Mt} / \mathrm{M}_{\infty}=\mathrm{Kt}^{\mathrm{n}}$

where, $k$ is release rate constant; $M t / M_{\infty}$ is fraction of drug concentration released at time t; $\mathrm{n}$ is release exponent. When $\mathrm{n}$ equals 0.5 , it is indicated as a Fickian or diffusion-controlled release and if $0.5<n<1.0$ then it is indicated as non-Fickian transport. If $n=1$, then it is zero order (case II transport).

Hixson-Crowell model:

$\mathrm{Mo}^{1 / 3}-\mathrm{M}^{1 / 3}=\mathrm{kt}$

where $M o$ and $M$ are the initial weight and weight of drug dissolved at time, $t$, respectively.

\section{Ex-vivo permeation studies}

\section{Tissue isolation}

From freshly slaughtered sheep, buccal tissue was obtained and stored in Krebs buffer $\mathrm{pH} 6.8$ at a temperature of $4{ }^{\circ} \mathrm{C}$. This study was approved by the Animal Ethics Committee, Faculty of Pharmacy, King Abdulaziz University (approval no. 423). The protocol complied with the guidelines of Declaration of Helsinki as well as the Principles in Care and Use of Animals (DHEW publication no .NIH 80-23) and "Principles of Laboratory Animal Care" (NIH publication \#85-23, revised in 1985). [16,17]The epithelium of mucosa was carefully isolated using a dissection procedure such that the basal marginal membrane was still intact and viable [16].

\section{Membrane permeability}

In a Franz diffusion cell, the sheep buccal membrane was mounted between the donor and acceptor compartment. The two chambers were tied to fix the buccal membrane. Phosphate buffer at $\mathrm{pH} 6.8$ was used as the medium inside the acceptor compartment with turbulence at 400 rpm. The optimized tablet (F4) was held inside the donor compartment. Sampling was done from the receptor compartment and an equal amount of medium was replaced in order to maintain sink conditions. $\mathrm{Mbv}-\mathrm{HCl}$ concentration in the withdrawn aliquots was calculated by the equation,

$\mathrm{J}=\mathrm{dQ} / \mathrm{A} d \mathrm{t}$

where $d Q / d t$ is the slope; $\mathrm{J}$ is the flux $\left(\mathrm{mg} \mathrm{h}^{-1}\right.$ $\left.\mathrm{cm}^{-2}\right)$ and $A$ is the diffusion area $\left(\mathrm{cm}^{2}\right)$.

\section{Stability studies}

Based on previous evaluation tests, we selected formulation (F4), which was subjected to accelerated stability studies at $25^{\circ} \mathrm{C} / 60 \% \mathrm{RH}$ and $40{ }^{\circ} \mathrm{C} / 75 \% \mathrm{RH}$ for 60 days in thermostatic ovens. At $0,15,30,45$, and 60 days, the tablets were tested for bioadhesive strength, content uniformity and drug release.

\section{Statistical analysis}

All the results in the present work are represented as mean \pm standard deviation (SD, $n$ $=3$ ). One-way ANOVA was used to calculate the difference in statistical significance at a probability level of 0.05 using Minitab 17. 


\section{RESULTS}

\section{Mbv-HCl mucoadhesive buccal properties of tablets}

Table 2 presents the physical parameters of each corresponding tablet. Hardness, thickness and surface $\mathrm{pH}$ were within the limits of uniformity. Variation in weight for batches $\mathrm{F} 1$ to F7 formulations was between $295.5 \pm 0.8$ and $304.4 \pm 0.5 \mathrm{mg}$. Tablet friability ranged from $0.113 \pm 0.03$ to $0.417 \pm 0.06 \%$ and drug content from $97.16 \pm 0.15$ to $103.21 \pm 0.42 \%$. The surface $\mathrm{pH}$ of the formulations is indicated in Table 2, and is in agreement with normal salivary of $\mathrm{pH} 5.5$ to 7.8 .

\section{In-vitro drug release}

Figure 1 indicates that release was different based on the polymer type and its ratio. The release order was determined as $\mathrm{F} 4>\mathrm{F} 3>\mathrm{F} 7>$ F6, as shown in Figure 1.

\section{Drug release kinetics}

Drug release kinetics are shown in Table 3 . The results showed that the drug released from formulations F2, F3, F4, F6, and F7 follow the Hixson-Crowell model (have higher $\mathrm{R}^{2}$ ), whereas $\mathrm{F} 1$ and $\mathrm{F} 5$ follow a zero-order release model.

\section{Bioadhesive strength}

Both type and concentration of the bioadhesive polymers affect bioadhesion characteristics. The strength of bioadhesion for $F 1$ to $F 7$ was found to be within the range of $20.21 \pm 0.82 \mathrm{~g}$ to $41.52 \pm$ $0.64 \mathrm{~g}$. Formulation $\mathrm{F} 4$ and $\mathrm{F} 7$ indicated maximum and minimum bioadhesive forces of about 4.073 \pm 0.06 and $1.982 \pm 0.09$, respectively. All the formulation results are shown in Table 4.

Table 2: Physicochemical properties of $\mathrm{Mbv}-\mathrm{HCl}$ buccal tablets

\begin{tabular}{|c|c|c|c|c|c|c|}
\hline $\begin{array}{l}\text { Formulation } \\
\text { code }\end{array}$ & $\begin{array}{l}\text { Hardness } \\
\text { (Kg/cm2) }\end{array}$ & $\begin{array}{l}\text { Thickness } \\
(\mathrm{mm})\end{array}$ & Weight (mg) & $\begin{array}{l}\text { Friability } \\
(\%)\end{array}$ & Surface $\mathrm{pH}$ & $\begin{array}{c}\text { Drug content } \\
\text { (\%) }\end{array}$ \\
\hline $\mathrm{F} 1$ & $5.5 \pm 0.02$ & $3.08 \pm 0.01$ & $295.5 \pm 0.8$ & $0.33 \pm 0.05$ & $6.91 \pm 0.06$ & $97.1 \pm 0.15$ \\
\hline F2 & $5.3 \pm 0.08$ & $3.15 \pm 0.02$ & $302.4 \pm 0.4$ & $0.41 \pm 0.06$ & $6.73 \pm 0.03$ & $102.5 \pm 0.34$ \\
\hline F3 & $5.6 \pm 0.03$ & $3.02 \pm 0.04$ & $298.2 \pm 0.3$ & $0.28 \pm 0.05$ & $6.50 \pm 0.04$ & $97.8 \pm 0.68$ \\
\hline $\mathrm{F} 4$ & $5.7 \pm 0.08$ & $2.98 \pm 0.02$ & $304.4 \pm 0.5$ & $0.24 \pm 0.03$ & $6.36 \pm 0.03$ & $103.2 \pm 0.42$ \\
\hline F5 & $5.9 \pm 0.04$ & $2.94 \pm 0.03$ & $301.3 \pm 0.2$ & $0.11 \pm 0.03$ & $6.71 \pm 0.02$ & $101.3 \pm 0.17$ \\
\hline F6 & $5.6 \pm 0.02$ & $3.03 \pm 0.01$ & $299.7 \pm 0.4$ & $0.29 \pm 0.07$ & $6.48 \pm 0.05$ & $98.2 \pm 0.27$ \\
\hline F7 & $5.8 \pm 0.03$ & $2.96 \pm 0.04$ & $300.2 \pm 0.2$ & $0.16 \pm 0.05$ & $6.16 \pm 0.05$ & $99.1 \pm 0.23$ \\
\hline
\end{tabular}

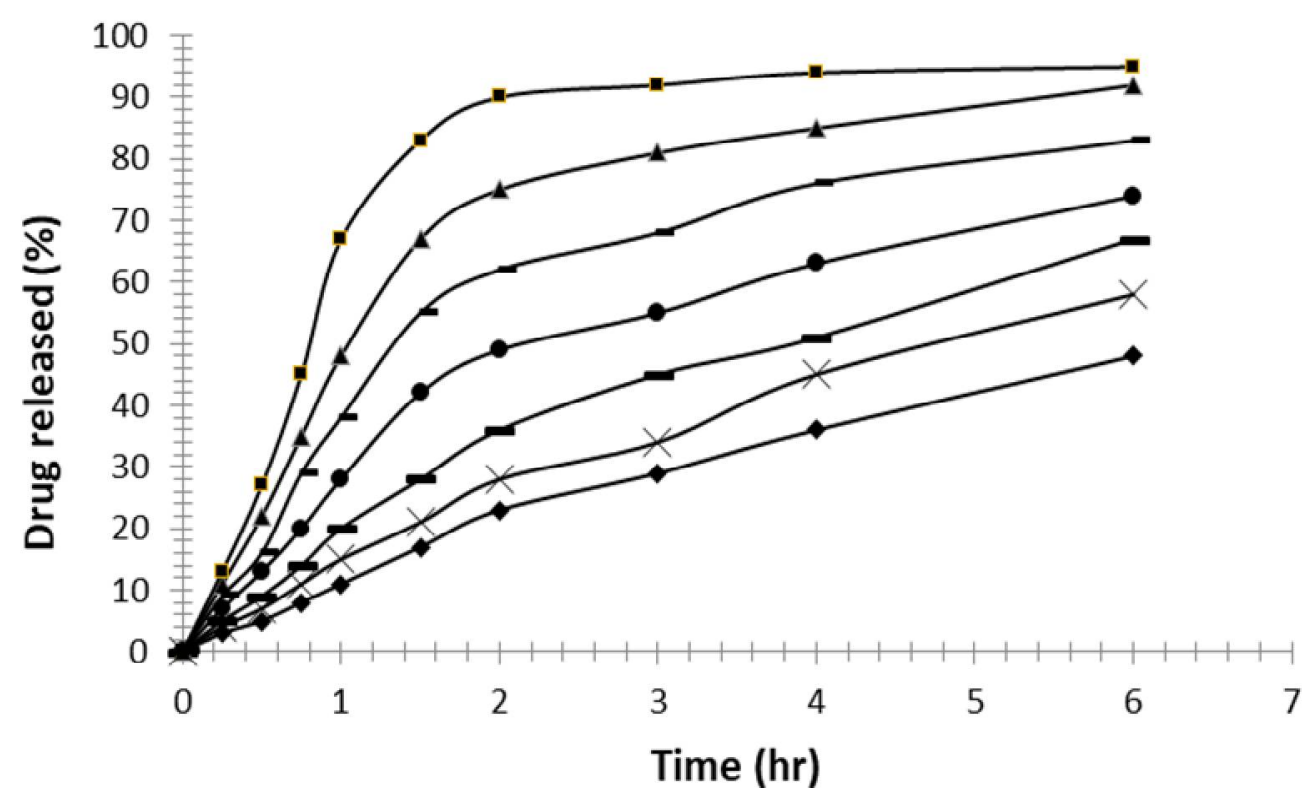

Figure 1: In-vitro cumulative drug release profile of $\mathrm{Mbv}-\mathrm{HCl}$ from different formulations $\mathrm{F} 1$ Carbopol 934P alone); F2 (- Carbopol 934P: HPMC 75:25); F3 (†- Carbopol 934P: HPMC 50:50); F4 (-a, Carbopol 934P: HPMC 25:75); F5 ( X Carbopol 934P: chitosan 75:25); F6 (-๑), Carbopol 934P: chitosan 50:50); F7 (- Carbopol 934P: chitosan 25:75) 
Table 3: Drug release kinetics of all $\mathrm{Mbv}-\mathrm{HCl}$ different formulations

\begin{tabular}{lccccc}
\hline $\begin{array}{l}\text { Formulation } \\
\text { code }\end{array}$ & Zero & First & $\begin{array}{c}\text { Hixson-Crowell } \\
\text { model }\end{array}$ & $\begin{array}{c}\text { Korsmeyer- } \\
\text { Peppas }\end{array}$ & Higuchi \\
\hline & $\mathrm{R}^{2}$ & $\mathrm{R}^{2}$ & $\mathrm{R}^{2}$ & $\mathrm{R}^{2}$ & $\mathrm{R}^{2}$ \\
F1 & 0.987 & 0.813 & 0.986 & 0.977 & 0.834 \\
F2 & 0.980 & 0.809 & 0.981 & 0.972 & 0.812 \\
F3 & 0.891 & 0.967 & 0.994 & 0.980 & 0.871 \\
F4 & 0.899 & 0.971 & 0.995 & 0.988 & 0.882 \\
F5 & 0.986 & 0.914 & 0.980 & 0.971 & 0.789 \\
F6 & 0.979 & 0.877 & 0.992 & 0.982 & 0.791 \\
F7 & 0.974 & 0.892 & 0.989 & 0.984 & 0.799 \\
\hline
\end{tabular}

Table 4: In-vitro bioadhesive strength and bioadhesive force for different $\mathrm{Mbv}-\mathrm{HCl}$ formulations

\begin{tabular}{lcc}
\hline $\begin{array}{l}\text { Formulation } \\
\text { code }\end{array}$ & $\begin{array}{c}\text { Bioadhesive } \\
\text { strength (g) }\end{array}$ & $\begin{array}{c}\text { Bioadhesive } \\
\text { force }(\mathbf{N})\end{array}$ \\
\hline F1 & $31.2 \pm 0.64$ & $3.06 \pm 0.05$ \\
F2 & $34.1 \pm 0.19$ & $3.35 \pm 0.08$ \\
F3 & $40.3 \pm 0.45$ & $3.95 \pm 0.07$ \\
F4 & $41.5 \pm 0.64$ & $4.07 \pm 0.06$ \\
F5 & $27.2 \pm 0.42$ & $2.67 \pm 0.04$ \\
F6 & $23.9 \pm 0.61$ & $2.34 \pm 0.06$ \\
F7 & $20.2 \pm 0.82$ & $1.98 \pm 0.09$ \\
\hline
\end{tabular}

\section{Swelling and ex-vivo residence time}

Formulations $\mathrm{F} 1$ to $\mathrm{F} 7$ have an ex-vivo residence time in the range of $200 \pm 15 \mathrm{~min}$ to $345 \pm 10$ min. The same formulas also have a swelling percent after $12 \mathrm{~h}$. The results are illustrated in Table 5. The highest swelling $(231.2 \pm 11.2 \%)$ was observed with formulation $\mathrm{F} 4$, and as as such was chosen for the ex vivo permeation study.

\section{Stability}

Formula 4 was stored at $25{ }^{\circ} \mathrm{C} / 60 \% \mathrm{RH}$ and 40 ${ }^{\circ} \mathrm{C} / 75 \% \mathrm{RH}$ for two months and was stable in different storage conditions, which is an important parameter for tablet evaluation (Table $6)$.

\section{Ex-vivo permeation}

F4 was the most promising formulation and was used to study the ex-vivo permeation profile of the drug through inexpensive buccal tissues because it has good moisture absorption and bioadhesive strength. The results show that $>80$ $\%$ of $\mathrm{Mbv}-\mathrm{HCl}$ permeated across the tissue in 6 h.

Table 5: Ex-vivo residence time and swelling (after $12 \mathrm{~h}$ ) for different Mbv-HCl formulations

\begin{tabular}{lcc}
\hline $\begin{array}{l}\text { Formulation } \\
\text { code }\end{array}$ & $\begin{array}{c}\text { Ex-vivo } \\
\text { residence time } \\
\text { (min) }\end{array}$ & $\begin{array}{c}\text { Swelling } \\
\text { (\%) }\end{array}$ \\
\hline F1 & $290 \pm 10$ & $151.4 \pm 7.1$ \\
F2 & $310 \pm 15$ & $192.2 \pm 8.9$ \\
F3 & $345 \pm 10$ & $214.5 \pm 9.7$ \\
F4 & $330 \pm 10$ & $231.2 \pm 11.2$ \\
F5 & $270 \pm 15$ & $163.2 \pm 9.2$ \\
F6 & $230 \pm 10$ & $178.4 \pm 5.9$ \\
F7 & $200 \pm 15$ & $197.2 \pm 8.6$ \\
\hline
\end{tabular}

\section{DISCUSSION}

Formulated mucoadhesive buccal tablets are promising in terms of adhering inside the oral space and sustaining the release of $\mathrm{Mbv}-\mathrm{HCl}$ over long periods. HPMC, and carbopol 934P are hydrophilic polymers, inert in nature and exhibit a high capacity to entrap a drug [18]. The high swellability of these polymers aids in their use for modified release systems [19]. Chitosan is a cationic charged biopolymer commonly used in formulations of controlled and sustained therapeutic delivery systems [20]. The incorporation of a therapeutic moiety into the polymer matrix forms a single lithic device.

Table 6: Stability of formulation F4 after storage for two months at $25{ }^{\circ} \mathrm{C} / 60 \% \mathrm{RH}$ and $40{ }^{\circ} \mathrm{C} / 75 \% \mathrm{RH}$

\begin{tabular}{|c|c|c|c|}
\hline Parameter & Pre-storage & $\begin{array}{c}\text { Post-storage (60 days at } \\
\left.25^{\circ} \mathrm{C} / 60 \% \mathrm{RH}\right)\end{array}$ & $\begin{array}{c}\text { Post-storage (60 } \\
\text { days at } 40^{\circ} \mathrm{C} / 75 \% \\
\mathrm{RH})\end{array}$ \\
\hline Drug Content (\%) & $103.2 \pm 0.42$ & $102.6 \pm 0.31$ & $100.1 \pm 0.62$ \\
\hline Bioadhesive-strength (g) & $41.5 \pm 0.64$ & $43.1 \pm 0.81$ & $40.0 \pm 0.52$ \\
\hline In vitro drug release (\%) & $91.2 \pm 3.21$ & $89.8 \pm 2.92$ & $87.9 \pm 3.07$ \\
\hline
\end{tabular}




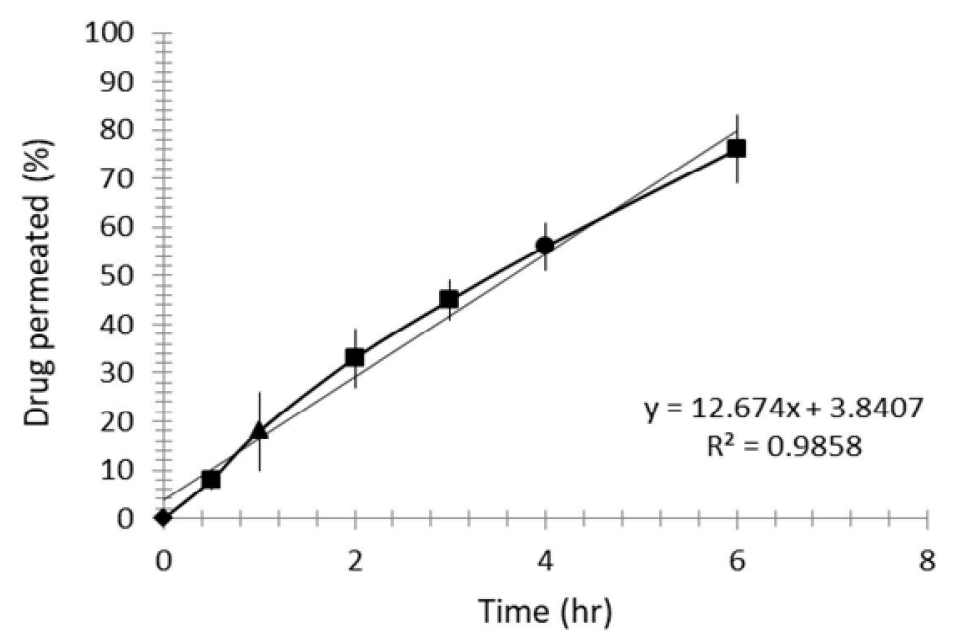

Figure 2: Ex-vivo permeation profile of $\mathrm{Mbv}-\mathrm{HCl}(-\mathrm{F} 4)$ across sheep buccal tissue

Purely on the basis of polymer concentration, film thickness around the tablet and the dissolution medium, the chemical entity release from the polymer filmed tablet can vary from hours to months [21].

Increasing the amount of hydrophilic polymer led to an increase in drug release rate. This is primarily because the polymers have the ability to absorb water, which enhanced dissolution and drug release. Additionally, the hydrophilic polymer creates a more porous structure and channel formation. The current study illustrates that the polymers, carbopol 934P, HPMC, and chitosan, which are hydrophilic polymers, in different ratios, result in different rates of drug release and different mucoadhesive force. For formulae F3 - F7, the drug release mechanism is erosion with a Hixson-Crowell model that describes the drug release mechanism from delivery systems with diameter as well as surface area changes in a respective tablet [22]. The kinetic data of formula F1 containing carbopol 934P only, and from F5, which contained the lowest concentration of secondary polymer (chitosan), fit perfectly with a zero-order model. This indicates that release was independent of drug concentration.

Increases in mucoadhesive strength by increasing the chitosan component was due to the interaction between the negative charge in the epithelium and the positive charge in chitosan. Changes in concentration and the type of bioadhesive polymer affect bioadhesive characteristics [23].

The swelling index was found to be the same for all the formulations F1 to F7. These results could be due to the presence of hydrophilic polymers in the formulation that will swell when coming into contact with water and enable a chain interaction within the mucin present in the buccal mucosa [24].

F4 formulation exhibited maximum permeation in comparison to other formulations. This could be attributed to the presence of a mucoadhesive polymer that ensures close contact between the drug and membrane. Additionally, the higher swelling index of this formula allows for the creation of pores and channels at the tablet surface, thus allowing ready diffusion of the drug through the tablets [25-27].

\section{CONCLUSION}

Mebeverine hydrochloride, a well-known antispasmodic drug, has been successfully formulated as a local anesthetic mucoadhesive buccal tablet. The optimum tablet formulation contains carbopol 934 and HPMC in a ratio of $1: 3$, and exhibits an ex-vivo residence time of $330 \mathrm{~min}$ in sheep buccal tissue. The formulation is stable after 6 months of storage. Further studies are required to determine its suitability for clinical use.

\section{DECLARATIONS}

\section{Acknowledgement}

This work was funded by the Deanship of Scientific Research (DSR), King Abdulaziz University, Jeddah, under grant No. (166-307D1435). The authors thank DSR for their technical and financial support.

\section{Conflict of Interest}

No conflict of interest associated with this work. 


\section{Contribution of Authors}

The authors declare that this work was done by the authors named in this article and all liabilities pertaining to claims relating to the content of this article will be borne by them.

\section{Open Access}

This is an Open Access article that uses a funding model which does not charge readers or their institutions for access and distributed under the terms of the Creative Commons Attribution License (http://creativecommons.org/licenses/by/ 4.0) and the Budapest Open Access Initiative (http://www.budapestopenaccessinitiative.org/rea d), which permit unrestricted use, distribution, and reproduction in any medium, provided the original work is properly credited.

\section{REFERENCES}

1. Baloglu E, Karavana SY, Hyusein IY, Kose T. Design and formulation of mebeverine $\mathrm{HCl}$ semisolid formulations for intraorally administration. AAPS PharmSciTech. 2010; 11: 181-188.

2. Elliott $S$, Burgess V. Investigative implications of the instability and metabolism of mebeverine. I Anal Toxicol. 2006; 30: 91-97.

3. Darvish-Damavandi M, Nikfar S, Abdollahi M. A systematic review of efficacy and tolerability of mebeverine in irritable bowel syndrome. World $J$ Gastroenterol. 2010; 16: 547-553.

4. Abdel-Hamid SM, Abdel-Hady SE, El-Shamy AH, ElDessouky HF. A novel formulation for mebeverine hydrochloride. Drug Dev Ind Pharm. 2007; 33: 10781089.

5. Saxena P, Gupta SK, Newaskar V, Chandra A. Advances in dental local anesthesia techniques and devices: An update. Natl J Maxillofac Surg. 2013; 4: 19-24.

6. Ogle OE, Mahjoubi G. Advances in local anesthesia in dentistry. Dent Clin North Am. 2011; 55: 481-499.

7. Ramacciato JG, Meechan JG. Recent advances in local anaesthesia. Dent Update. 2005; 32(1): 8-10.

8. Sudhakar Y, Ketousetuo KK, Bandyopadhyay AK. Buccal bioadhesive drug delivery- A promising option for orally less efficient drugs. J Control Release. 2006; 114: 1540.

9. Longer MA. Robinson JR. Fundamental aspects of Bioadhesion. Pharm. Int. 1986; 7: 114-117.

10. Nafee NA, Ismail FA, Boraie NA, Mortada LM. Mucoadhesive delivery systems. II. Formulation and invitro/in-vivo evaluation of buccal mucoadhesive tablets containing water-soluble drugs. Drug Dev Ind Pharm. 2004; 30(9): 995-1004.

11. Pratima N, Tiwari S, Kamble S. Mucoadhesive: As Oral Controlled Gastroretentive Drug Delivery System. Int. J. Res. Dev. Pharm. Life Sci.2012; 2(3): 32-59.
12. Javad S., Deshpande A. Sarab A. Evaluation of buccal tablets of salbutamol. Acta Pharm. Technol. 2014; 5(2): 137-141.

13. Goud B, Samanthula K. Formulation and evaluation of bioadhesive tablets of simvastatin. Int. J. Adv. Res. Pharm. Bio Sci. 2011; 1(1): 68-91.

14. Velmurugan $S$, Spinivas $P$. Formulation and in vitro evaluation of losartan potassium mucoadhesive buccal tablets. Asian J. Pharm. Clin. Res. 2013; 6(3): 125-130.

15. John S, Sathesh R, Divakar G, Manoj K, Jangid and Kapil. Development and evaluation of buccoadhesive drug delivery system for Atorvastatin calcium. Int. J. Curr. Pharm. Res. 2010; 01: 31-38.

16. NIH Guide for the care and use of laboratory animals. Special edn: Laboratory Animal Welfare. 1985;1 4(8)

17. Reinhardt V. Comfortable quarters for sheep in research institutions. Comfortable Quarters for Laboratory Animals, 9th edn. Washington: Animal Welfare Institute. 2002: 83-88.

18. Roy S, Pal K, Anis A, Pramanik K, Prabhakar B. Polymers in Mucoadhesive Drug Delivery System: A Brief Note. Des. Monomers Polym. 2009; 12: 483-495.

19. Gandhi S, Pandya P, Umbarkar R, Tambawala T, Shah M. Mucoadhesive drug delivery system- an unusual maneuver for site specific drug delivery system. Int. J. Pharmaceut Sci. 2011; 2(3): 132-152.

20. Fu XC, Wang GP, Liong WQ, Chou MSS. Predication of drug release from HPMC matrices: effect of physicochemical properties of drug and polymer concentration. J. Controll. Rel, 2004; 95: 209-216.

21. Siepmann J, Peppas NA. Modeling of drug release from delivery systems based on hydroxypropyl methylcellulose (HPMC). Adv Drug Deliv Rev, 2001; 48: 139-157.

22. Rao YM, Vishnu YV, Chandrasekhar K, Ramesh G. Development of Mucoadhesive patches for buccal administration of Carvedilol. Curr. Drug Delivery. 2007; 4: 27-39.

23. Lacan M, Jug M. Influence of hydroxypropyl-cyclodextrin complexation on piroxicam release from buccoadhesive tablets. Eur J Pharm Sci. 2012; 21: 251-260.

24. Chen S, Zhu J, Cheng J. Preparation and in vitro evaluation of a novel combined multiparticulate delayedonset sustained-release formulation of diltiazem hydrochloride. Pharmazie. 2007; 62(12): 907-913.

25. Sonia TA, Sharma CP. Chitosan and its derivatives for drug delivery perspective. Adv Polym Sci. 2011; 243: 23-54.

26. Cerchiara T, Luppi B, Bigucci F, Petrachi M, Orienti J, Zecchi $V$. Controlled release of vencomycin from freezedried chitosan salts coated with different fatty acids by spray - drying. J. Microencapsulation, 2003; 20: 473478.

27. Puttipipatkhachora S, Nunthanid J, Yamamoto K, Peck GE. Drug physical state and drug - polymer interaction on drug release from chitosan matrix films. J. Controll. Rel, 2001; 75: 143-153.

Trop J Pharm Res, August 2017; 16(8): 1812 
Abdulhady \& Ibrahim

Trop J Pharm Res, August 2017; 16(8): 215 